\title{
ANÁLISE DAS SIMILARIDADES ENTRE COLHERES PRODUZIDAS COM AÇO INOXIDÁVEL ${ }^{1}$
}

\author{
Guilherme Vieira Braga Lemos ${ }^{2}$ \\ Diego Belato Rosado ${ }^{2}$ \\ Leandro Medeiros da Silva ${ }^{2}$ \\ Bill Paiva dos Santos ${ }^{3}$ \\ Jefferson $\mathrm{Haag}^{3}$ \\ Vagner Machado Costa ${ }^{3}$ \\ Luciana Morellato Medeiros ${ }^{3}$ \\ Diego Moises Maciel Vieira ${ }^{4}$ \\ Telmo Roberto Strohaecker ${ }^{5}$
}

\begin{abstract}
Resumo
A análise de similaridades é uma das maneiras de se avaliar e comparar as características entre produtos. Neste contexto, a seleção de materiais é essencial no design e fabricação de peças. Para escolher o melhor material devemos levar em conta às diversas questões envolvidas como: confiabilidade, funcionalidade, segurança, custos e questões ambientais. O desempenho de um componente pode ser especificado através dos requisitos funcionais, da geometria e também das propriedades do material. Sendo assim, o presente trabalho teve como intuito principal a avaliação das semelhanças e diferenças entre colheres, produzidas com aço inoxidável, de diferentes preços e fabricantes (nacionais e importados) disponíveis no mercado. Com os resultados obtidos foi possível caracterizar os materiais e correlaciona-los quanto as suas diferenças.
\end{abstract}

Palavras-chave: Design de materiais; Análise de similaridades; Colheres; Aço inoxidável.

\section{SIMILARITIES ANALYSIS OF SPOONS MADE WITH STAINLESS STEEL}

\author{
Abstract \\ The analysis of similarities is one of the ways to evaluate and compare the features \\ between products. In this context, the selection of materials is essential in the design \\ and manufacturing of parts. To choose the best material we take into account the \\ various issues involved such as: reliability, functionality, safety, cost and \\ environmental issues. The performance of a component can be specified by the \\ functional requirements, geometry and also the material properties. Thus, the present \\ study aims to evaluate of the similarities and differences between spoons, made with \\ stainless steel, and prices of different manufacturers (national and imported) \\ available in the market. With these results it was possible to characterize the \\ materials and correlates their differences. \\ Key words: Materials design; Similarities analysis; Spoons; Stainless steel.




\section{INTRODUÇÃO}

A aplicação de ideias inovadoras relacionadas ao projeto de produtos, bem como a criação de novos métodos de produção são técnicas diariamente aprimoradas em todo o mundo. Sendo assim, os principais objetivos propostos por estas mudanças são: a redução do tempo de fabricação, diminuição de custos e os designs inovadores, isto porque os consumidores estão cada vez mais exigentes e desejam produtos diferenciados e competitivos. Desta forma, as empresas que buscam aumentar a sua presença no mercado ou mesmo implantar novos produtos têm dado uma maior atenção aos projetos de seus componentes com foco na aparência, forma e tamanho com estes fatores aliados a um baixo custo de fabricação. Atualmente um fabricante que não considera esses fatores como projeto, seleção de materiais, adequação ao processo de fabricação e inovação está condenado a perder mercado. ${ }^{(1-4)}$ Tendo em vista o aumento na importação de produtos provenientes de países como China e Taiwan cujos preços são, na maioria dos casos, inferiores aos dos produzidos no Brasil, e a diversidade de materiais que podem ser selecionados, surge uma necessidade de estudar as diferenças destes produtos, avaliar seus materiais e os processos de fabricação através de uma análise de similares. ${ }^{(5)}$

\section{MATERIAIS E MÉTODOS}

De acordo com a metodologia empregada no trabalho foram realizadas as seguintes análises nas colheres em aço inoxidável: composição química, ensaios de tração, metalografia e perfil de microdureza. A amostragem do estudo foi classificada com respeito à cor da colher, marca e preço de mercado conforme mostra a Tabela 1.

Tabela 1. Amostragem, colheres, marcas e preços de compra.

\begin{tabular}{|c|c|c|c|}
\hline Amostragem & Colher (cor) & Marca & Preço (R\$) \\
\hline & Madeira & Tramontina & 4,20 \\
\hline & Preta & Tramontina & 2,20 \\
\hline & Amarela & Tramontina & 1,50 \\
\hline & Verde & Chinesa & 0,80 \\
\hline
\end{tabular}

A caracterização dos materiais encontrados nos cabos das colheres foi realizada através da técnica FTIR (Espectroscopia de Infravermelho) que serve basicamente para verificar os constituintes poliméricos dos cabos do material.

A composição química (\% em massa), apresentada na Tabela 2, dos elementos particularmente presentes no aço que compõe a colher foi realizada em um espectrômetro de centelha Spectro. O princípio deste método é fazer com que o material da amostra seja vaporizado por uma descarga de arco elétrico (conhecido como centelha). Os átomos e íons contidos no vapor atômico são excitados para emissão de radiação. A radiação emitida é transmitida para o espectrômetro através de fibras ópticas, onde se dispersa em componentes espectrais. Como 
procedimento padrão foram realizadas três queimas em cada amostra a fim de obter uma média como resultado final.

Para a análise metalográfica, seguindo os procedimentos convencionais e usuais atualmente, em um primeiro passo as amostras foram cortadas em uma máquina Skill-TEC CSK 80 e depois embutidas em uma Struers Labopress 3. Depois do embutimento, a superfície a ser analisada foi lixada sequencialmente por uma série de lixas mesh com diferentes granulometrias no intervalo de 220 e 1.200. Em seguida, foi realizado o polimento das superfícies com pasta de diamante de granulometria $3 \mu \mathrm{m}$, em uma politriz Struers DP-10. Por fim, a superfície foi atacada quimicamente com uma solução de $\mathrm{HCl} 50 \%$ e tempo imersão variando entre 10 e 20 segundos. Então, as amostras foram analisadas com um microscópio ótico Olympus BX51M com o objetivo de identificar a microestrutura do material.

As medições de microdureza Vickers, da superfície em direção ao núcleo, foram realizadas em um equipamento microdurômetro eletrônico Instron, aplicando uma carga de 300 gramas.

A resistência ao arrancamento foi avaliada através do ensaio de tração. As colheres foram posicionadas verticalmente em uma máquina de ensaios mecânicos MTS 810 Material Test System onde foram aplicadas diversas cargas até o rompimento.

\section{RESULTADOS}

Os elementos químicos dos aços inoxidáveis presentes nas colheres podem ser visualizados na Tabela 2. Notaram-se algumas diferenças com relação a composição química de alguns elementos especificamente, dentre eles podem-se citar: manganês, níquel e nióbio.

Tabela 2. Composição química (\% em massa) das colheres

\begin{tabular}{|c|c|c|c|c|c|c|c|c|c|c|}
\hline Amostras & $\mathbf{C}$ & $\mathbf{S i}$ & $\mathbf{M n}$ & $\mathbf{P}$ & $\mathbf{C r}$ & $\mathbf{M o}$ & $\mathbf{N i}$ & $\mathbf{C u}$ & $\mathbf{N b}$ & $\mathbf{V}$ \\
\hline Madeira & 0,06 & 0,45 & 0,16 & 0,04 & 16,6 & 0,04 & 0,22 & 0,01 & 0,43 & 0,03 \\
\hline Preto & 0,07 & 0,32 & 0,38 & 0,02 & 16,8 & 0,04 & 0,27 & 0,06 & 0,01 & 0,09 \\
\hline Amare/o & 0,05 & 0,38 & 0,20 & 0,03 & 16,5 & 0,03 & 0,19 & 0,02 & 0,44 & 0,03 \\
\hline Verde & 0,07 & 0,37 & 0,49 & 0,02 & 16,4 & 0,03 & 0,15 & 0,06 & 0,01 & 0,09 \\
\hline
\end{tabular}

As metalografias tiveram, principalmente, o objetivo de caracterizar a microestrutura proveniente dos aços das colheres. As quatro micrografias (Figura 2) mostraram a presença de ferrita (provavelmente relacionada um aço inox ferrítico) e alguns pequenos carbonetos precipitados. 

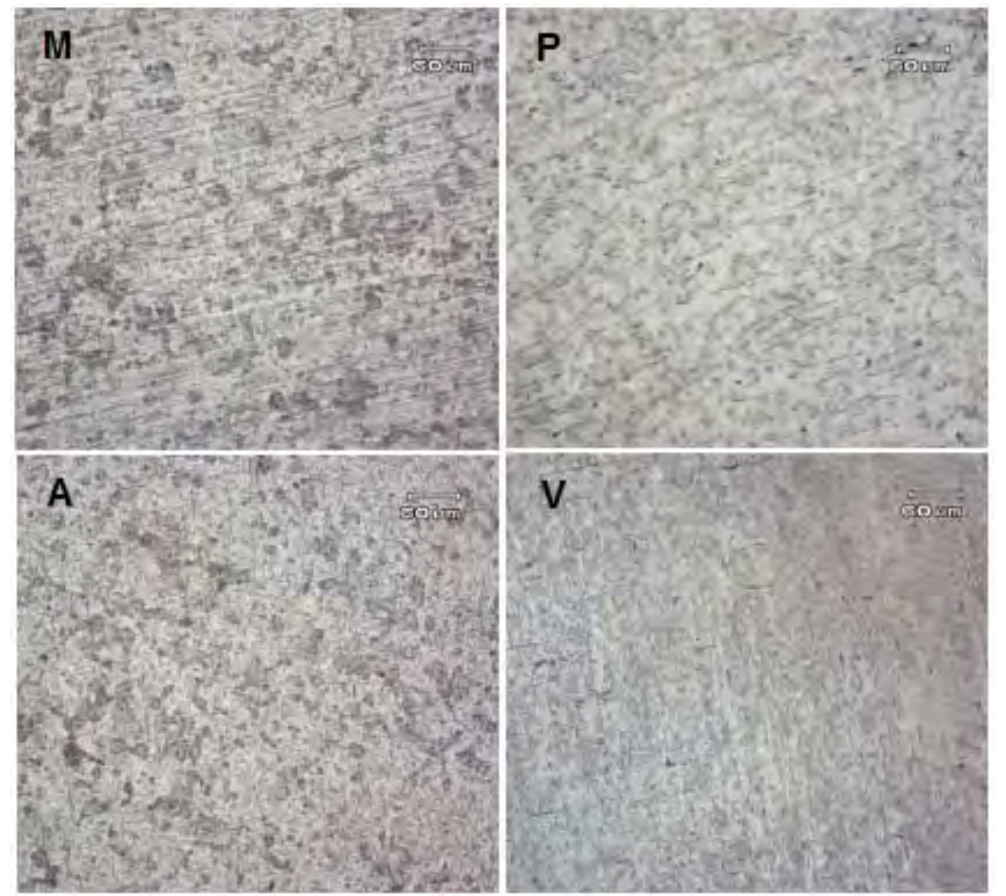

Figura 2. Microestruturas em aumento de 200x: (M) Madeira; (P) Preto; (A) Amarelo; (V) Verde.

Os resultados do ensaio de tração (Figura 3) mostraram que três dentre todas as colheres (preto, amarelo e verde) apresentaram comportamento semelhante com força máxima de $250 \mathrm{~N}$, aproximadamente. Enquanto a colher com cabo em madeira, indicando uma maior qualidade também, alcançou $5500 \mathrm{~N}$ de força axial, ou seja, suportou 22 vezes mais o esforço submetido do que as outras colheres.

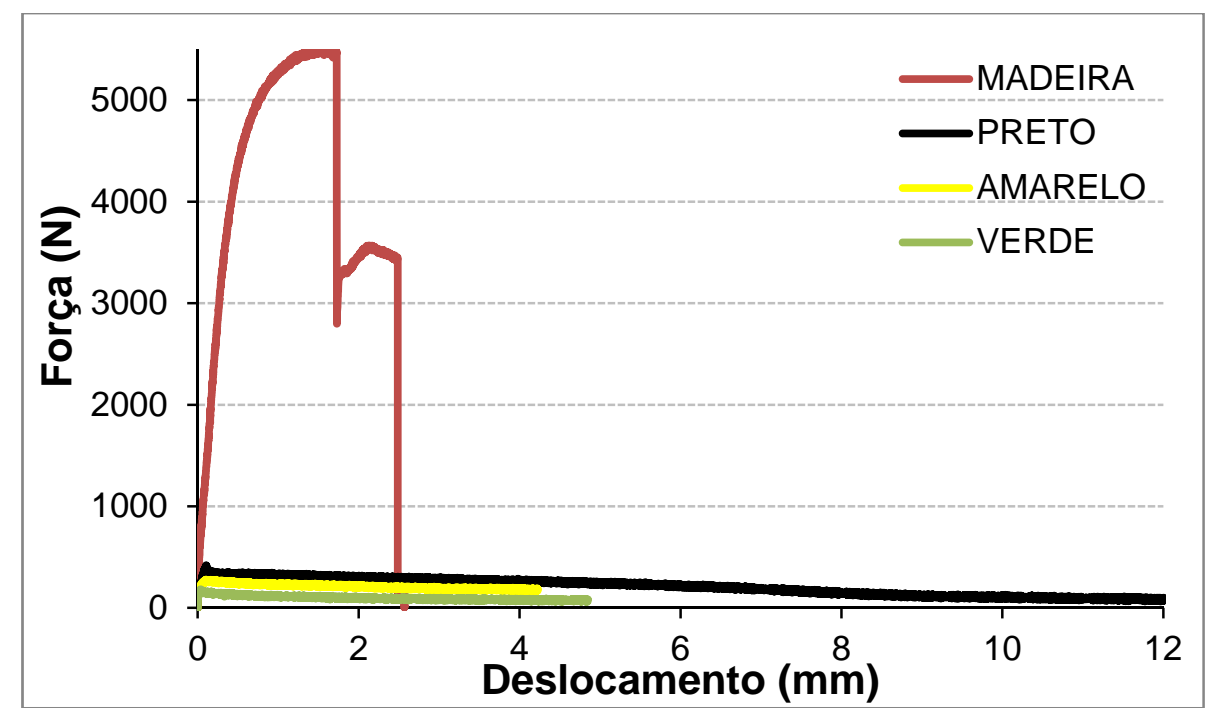

Figura 3. Comparações no ensaio de arrancamento entre as colheres analisadas.

Em quase todos os casos, as colherem foram arrancadas de seus cabos, exceto a colher com cabo de madeira onde existiam dois pinos de sustentação que suportaram melhor os esforços de tração no material. O resultado dos produtos após os ensaios de arrancamento das colheres é apresentado pela Figura 4. 


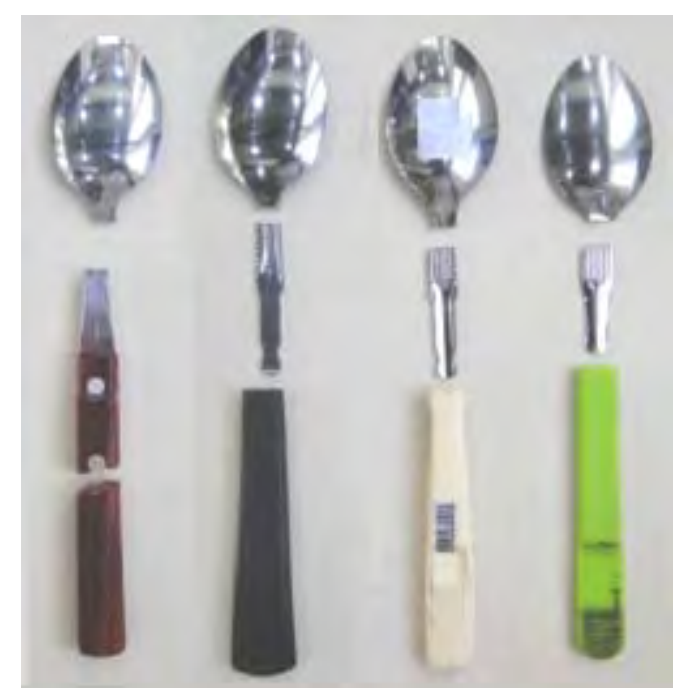

Figura 4. Colheres após ensaio de arrancamento.

Com relação aos perfis de microdureza das amostras, o gráfico da Figura 5 mostra as medições ao longo dos aços em uma seção transversal partindo da superfície $(0 \mathrm{~mm})$ até uma distância de $3,5 \mathrm{~mm}$ em direção ao núcleo. Três dos materiais alcançaram um perfil de microdureza praticamente igual, enquanto que apenas a colher com cabo preto mostrou um comportamento distinto. Provavelmente, este fato é devido a algumas diferenças microestruturais localizadas e/ou variações de composição química nos materiais analisados conforme já mencionado anteriormente.

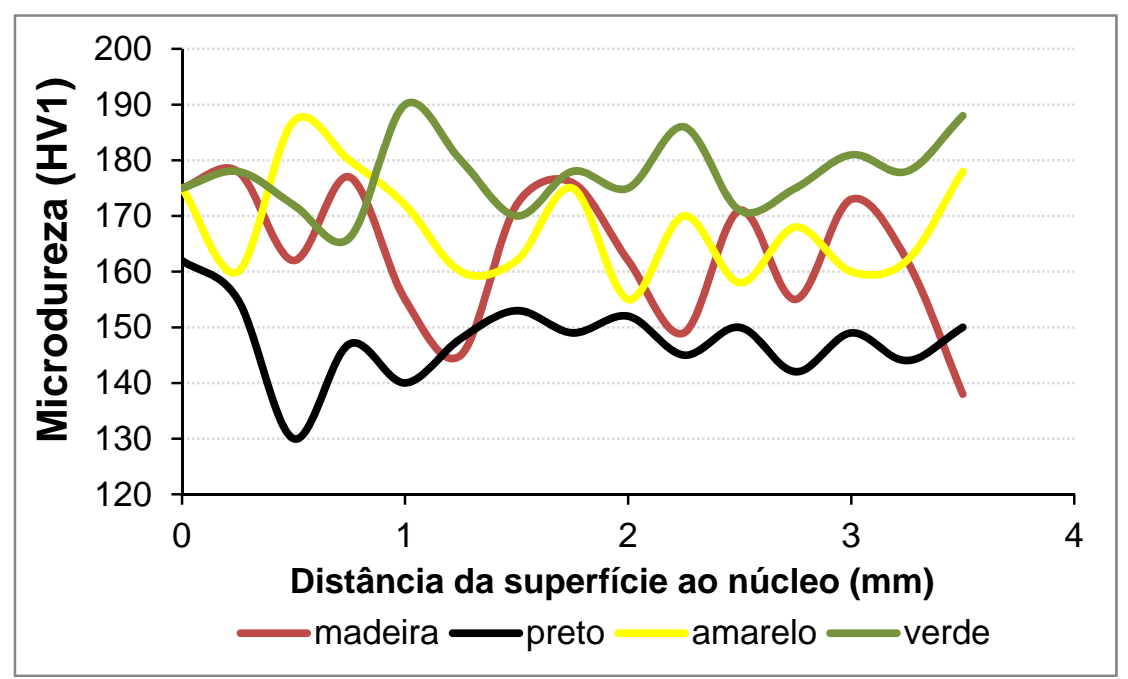

Figura 5. Comparação entre os quatro perfis de dureza para as amostras em aço inox.

Por outro lado, conforme pode ser visto na Figura 6, são apresentadas as médias de microdureza calculadas. Nota-se que a amostra mais barata (verde) tem maior média de microdureza e uma menor variação deste valor quando comparada as outras colheres. 


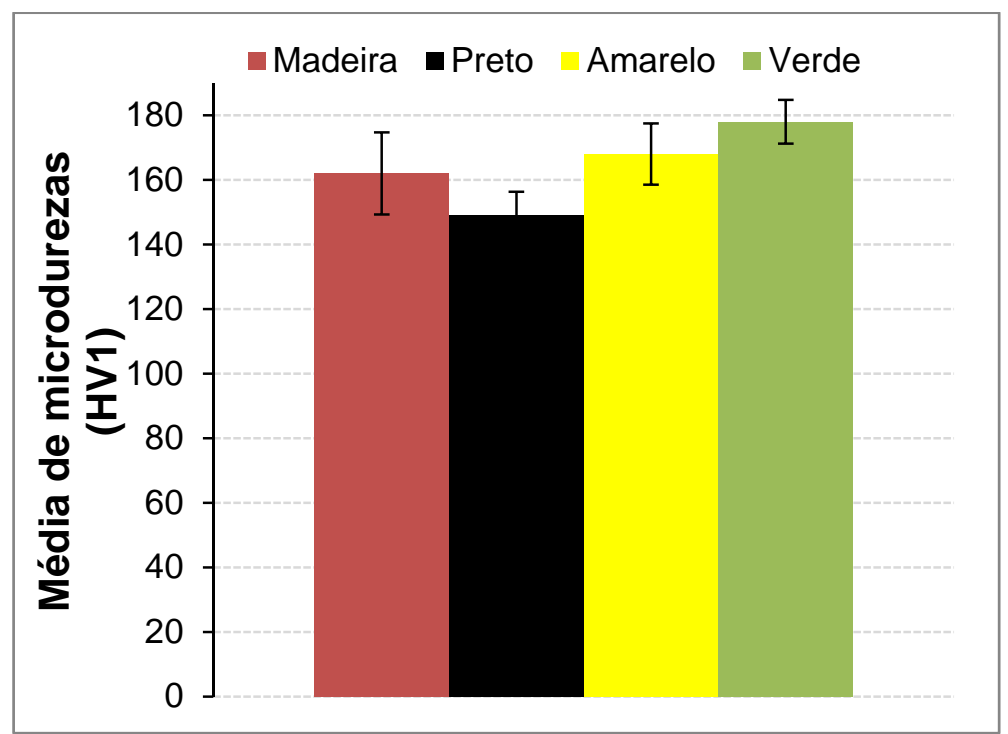

Figura 6. Médias de microdureza para as amostras.

As análises de FTIR do material encontrado nos cabos das colheres são apresentadas através das Figuras 7, 8, 9 e 10.

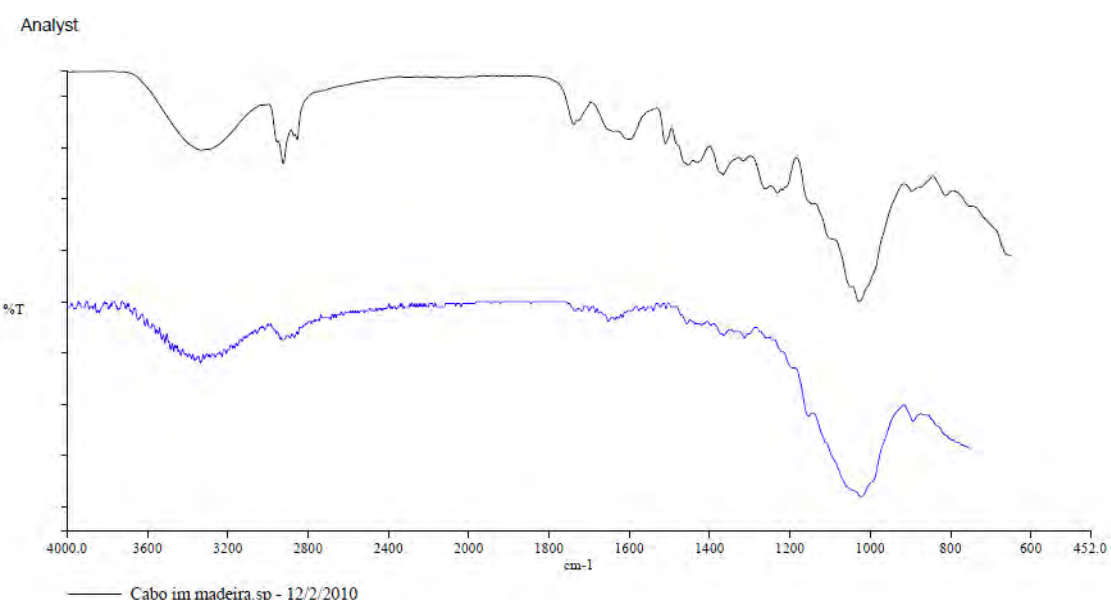

W W00770.sp - 12/2/2010 - W00770 THERMO-CERAM

Figura 7. Composição química da resina do cabo "em madeira".

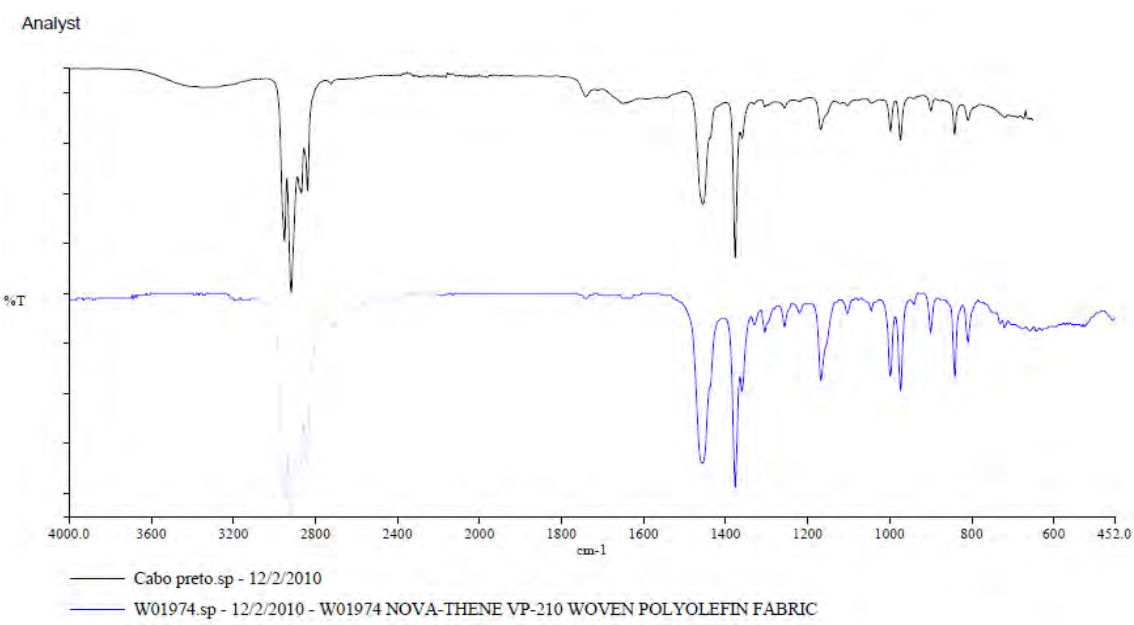

Figura 8. Composição química do cabo preto. 


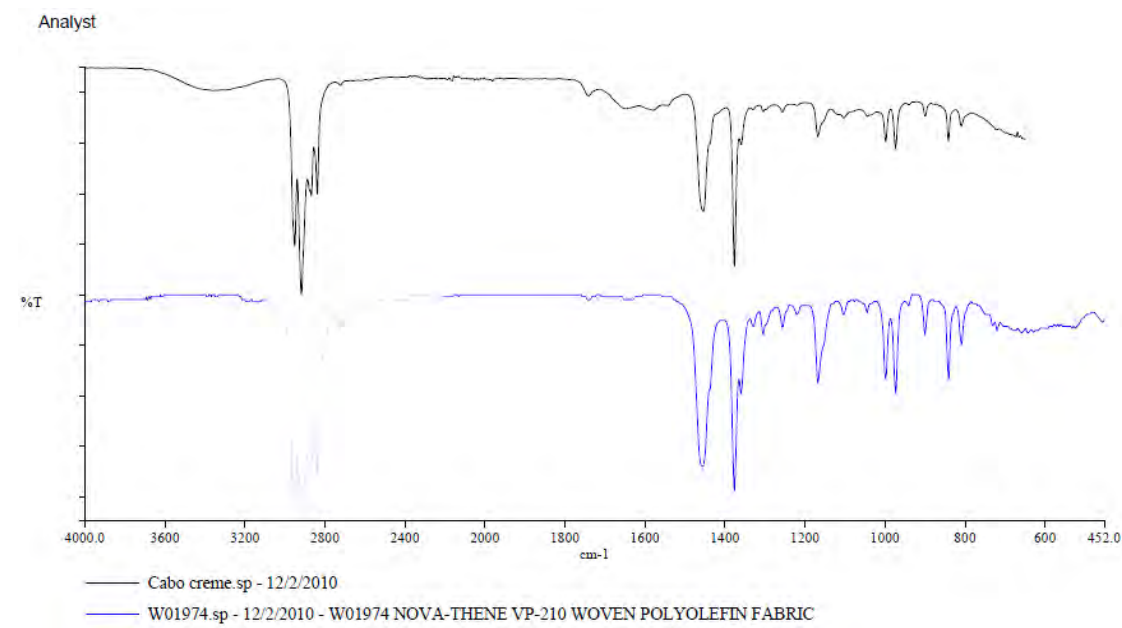

Figura 9. Composição química do cabo amarelo.

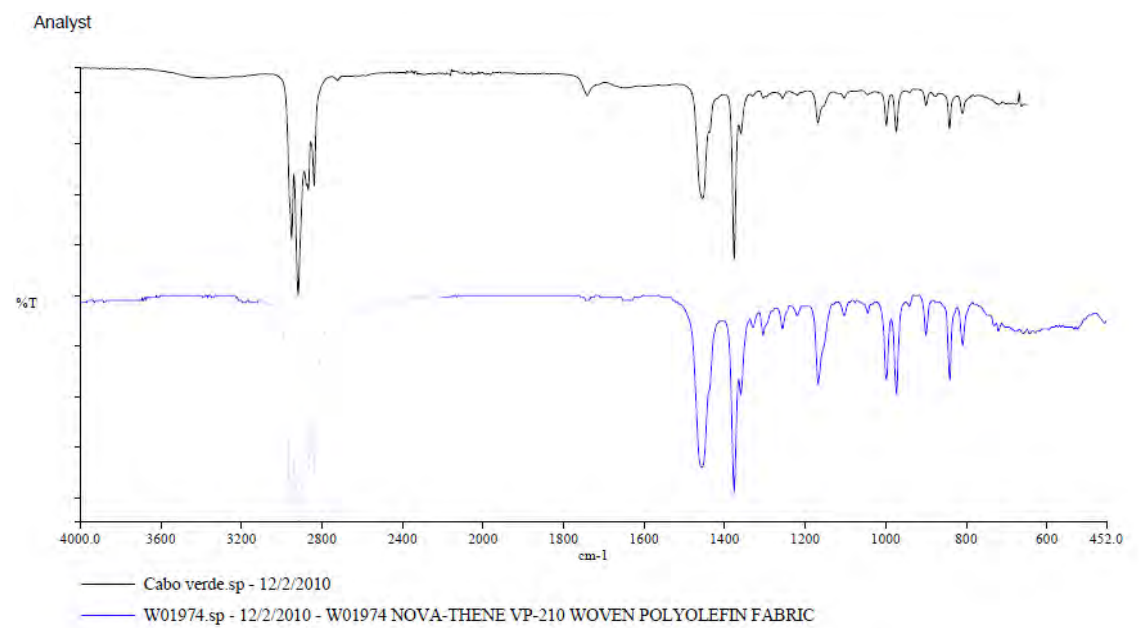

Figura 10. Composição química do cabo amarelo (colher de aço inoxidável).

As colheres com as seguintes cores de cabo: verde, amarelo e preto obtiveram predominância do material com nome comercial de Nova Thene VP 210 - Woven Polyolefin Fabric, ou seja, os cabos foram produzidos com polipropileno. A colher com cabo "em madeira" mostrou espectro semelhante ao do material W00770 Thermo Ceram que é uma resina utilizada pelo fabricante para proteger a madeira.

\section{DISCUSSÕES}

Para a maioria dos ensaios, as três amostras mais baratas (preta, amarela e verde) apresentaram resultados bastante similares. Isso provavelmente se deve a composição química semelhante em relação ao aço inoxidável. A microestrutura foi basicamente ferrita. O aspecto visual destas colheres é mais simples, indicando alguma economia em custos, design e processamento.

Com respeito ao ensaio de tração, a colher com cabo em madeira demorou mais tempo para ser desprendida (arrancada de sua base). Ela suportou cargas maiores para do que as outras colheres analisadas. Este comportamento é proveniente, provavelmente, dos dois pinos de sustentação do cabo, que contribuíram para aumentar a resistência do componente, tanto ao arrancamento do cabo quanto a fratura do aço. 


\begin{abstract}
Através da caracterização do material presente nos cabos das colheres percebe-se que três delas (a de cor verde, amarelo e preto) foram produzidas com polipropileno. Com relação à colher com cabo de madeira descobriu-se que a mesma é protegida por uma resina chamada Thermo-Ceram que conforme indicação do fabricante aumenta a sua vida útil do cabo. Isso pode explicar o porquê do o preço da colher de madeira ser mais elevado (diferenças na composição química, pinos de sustentação no cabo e resina protetora como diferenciais das demais colheres).
\end{abstract}

\title{
5 CONCLUSÕES
}

Os resultados apresentados neste trabalho permitem as seguintes conclusões:

- os ensaios realizados serviram para caracterizar os materiais que compõem as quatro colheres escolhidas para análise das similaridades; e

- a colher de madeira é a que apresenta as melhores propriedades mecânicas e, sendo assim, possivelmente uma maior durabilidade. Isto é resultado da maior resistência obtida no ensaio de tração e proteção pela resina ThermoCeram do cabo de madeira. Fazem-se ressalvas quanto ao custo porque a colher chinesa (verde) tem boas propriedades e melhor relação custo beneficio (dependendo das suas condições de uso), quando comparada as outras da marca Tramontina.

\section{Agradecimentos}

Devido à colaboração, auxilio nos ensaios e disponibilidade dos equipamentos, agradecemos os seguintes laboratórios: LdSM (Laboratório de Design e Seleção de Materiais) e o LAMEF (Laboratório de Metalurgia Física) ambos da UFRGS (Universidade Federal do Rio Grande do Sul).

\section{REFERÊNCIAS}

1 ASHBY, M. F. Materials Selection in Mechanical Design. 2005.

2 ASM Handbook. Materials Selection and Design. 2005.

3 KANEFUKU, J. Y. Influência do Traje de Alta Tecnologia Blueseventy no Desempenho em Natação. UFRGS. 2009.

4 MARQUES, A. C. Análise de Similares: Contribuição ao Desenvolvimento de Uma Metodologia de Seleção de Materiais E Ecodesign. Tese de Mestrado. Programa de Pós Graduação em Engenharia de Minas, Metalúrgica e Materiais. UFRGS. 1998.

5 SCHNEIDER, E. L. et al. Seleção de Materiais: Estudo em chaves de fenda. CBECIMat. 2006. 